\title{
El espacio urbano como recurso social en la novela de Proust
}

Catherine Bidou-Zachariasen Universidad de París-Dauphine/CNRS

El propósito de este artículo es mostrar la manera como el análisis social central de la novela de Proust En busca del tiempo perdido (es decir, aquel que aborda las relaciones entre la aristocracia y la burguesía), trata la dimensión espacial. El espacio residencial, esencialmente urbano y parisino, representa allí más que el mero símbolo de un lugar o de una clase social. Igualmente, desborda el cuadro, la escena en que se juegan las interacciones sociales. Proust también lo construyó como un recurso a partir del cual se elaboran las estrategias de los actores. En este sentido, el espacio residencial es tanto la forma de analizar las relaciones sociales, como el operador de éstas.

A fines del siglo XIX la aristocracia, que había visto restringir progresivamente su poder político y luego económico, al menos conservaba la supremacía social. Ciertas capas burguesas iban a acometerla en esa supremacía, su última fortaleza. Para triunfar, esta empresa tenía que inscribirse en un territorio. Es en esta perspectiva que el autor sitúa su análisis del salón burgués mundano. Este juego territorial transcurre sobre todo en París, en una compleja profusión de escenas "mundanas", cuya organización temporal es a veces difícil de captar; el autor reconstruye los estados sucesivos de los campos aristocráticos y burgueses. A lo largo de los primeros volúmenes de la novela, el autor revela que la institución de la "Casa" aristocrática se expresaba completamente a través de su territorio, aquel donde el grupo estaba ins-

Economía, Sociedad y Territorio, vol. II, núm. 6, 1999, 191-212. 
crito desde hacía siglos (la tierra y el castillo de los ancestros) ${ }^{1}$ y que en general se ha desdoblado de modo más reciente por medio de una residencia urbana. La aristocracia aún no había marcado más significativamente su espacio; en esta época ella era territorio.

La burguesía de la novela es pintada en toda su diversidad, pero el autor desarrollará más particularmente dos variantes: Una más tradicional, que había optado por imitar a la aristocracia, ciñéndose más a sus valores y comportamientos, representada esencialmente por el salón de la señora Swann, conservador (en sentido político) y conformista (en sentido social); la otra variante de la burguesía muy desarrollada en la novela, es más innovadora, corresponde al salón de la señora Verdurin, en la que se intentaba volver a juzgar la legitimidad social aristocrática. Por esto, esta burguesía nueva había retenido un plan de ataque, la Cultura, detectada por ella como el punto débil de esta casta, fijado desde siglos atrás y permaneciendo al margen de los conocimientos y las nuevas ocupaciones. Ella también había privilegiado una estrategia, la lucha simbólica; es decir, todo un trabajo sobre las representaciones sociales y las visiones del mundo. En sus salones, esta burguesía había participado en la "invención" del art nouveau, enardecido para el combate político, proponiendo la figura del "intelectual” y el artista comprometido.

Sin embargo, estas capas sociales con intensa movilidad social no tenían ninguna antigüedad de inscripción territorial. Si lo que había en juego en el salón de la nueva burguesía era el llegar a crear nuevos valores, visiones alternativas del mundo, este trabajo simbólico también debía, para ser más eficaz, materializarse por medio del espacio. Es por esto que los salones burgueses con pretensiones intelectuales y artísticas, como el de la señora Verdurin, se esforzaban por concretar la nueva moneda que se constituía en su seno. Esta materialización espacial era una forma de capitalizar, es decir, también de hacer más durable una moneda simbólica, por naturaleza volátil. El “trabajo de salón”, así, es jugado en un doble nivel: el de lo simbólico y el de la práctica, que se refuerzan el uno al otro. Las luchas simbólicas, como trabajo cognitivo sobre las representaciones, toman cuerpo y realidad mediante las cualidades formales -que también son simbóli-

${ }^{1}$ M. de Saint Martin en L'espace de la noblesse (ediciones Métailié, 1993) muestra cómo para este grupo social la descendencia se inscribe íntimamente en su espacio, "el castillo es presentado y vivido por los aristócratas como el lugar por excelencia" (p. 95). También en Eric Mension-Rigau, L'Enfance au château, Ediciones Rivages, 1990. 
cas- de los lugares en donde ellas son puestas en práctica. Pero si la estrategia territorial de la burguesía se ha jugado mucho en los salones, tal como se testimonia a lo largo de toda la novela, esta estrategia es indisociable de una investidura socio-territorial, la de un espacio público urbano específico que no existía anteriormente como tal y que consagrará su visibilidad.

La sobreinvestidura espacial, tanto pública como privada, cuya prueba son las nuevas capas burguesas de la novela, también puede ser interpretada como una dimensión compensatoria, sobreinvestida en razón misma del déficit de tiempo, lo que ha marcado a las capas sociales recientemente emergidas en la escena social, con una identidad social aún mal establecida. ${ }^{2}$ Ahora bien, la inscripción espacio-temporal en dondequiera es constitutiva de las identidades, ya sea que se trate de una clase, de un grupo social, o de una sociedad tradicional. "El espacio y el tiempo fuera de los cuales, nada de lo real se puede construir", escribía Cassirer. ${ }^{3}$ En este sentido, la institución de los salones de los siglos XVIII y XIX, como espacialización y materialización de capital simbólico, ha sido eficaz. Esta institución (los salones) ha participado en la instalación de las capas sociales en ascenso, dentro de la estructura social, es decir, aquellas capas sociales con problemas de identidad y en búsqueda de legitimidad. Esto representa el análisis que Proust ha hecho.

Es esta geografía social expuesta en la novela En búsqueda del tiempo perdido, su evolución y las estrategias de ascenso o de preservación social a las cuales ella ha correspondido, que nosotros vamos a reconstruir aquí. Para esto seguiremos el plan según el cual es construida la historia social de la novela, que presenta, alternativamente y en un periodo de una cuarentena de años, una serie de escenas aristocráticas y burguesas, en las cuales el autor multiplica y complica las diversas figuras.

2 Éste es el mismo proceso que he observado entre las clases medias asalariadas ligadas al Estado Benefactor, en ascenso durante los "treinta gloriosos"; capas sociales en búsqueda de una identidad y en un periodo de fuerte trabajo ideológico, es decir, simbólico, que han materializado su visibilidad naciente por la emergencia masiva de su espacio del poder local. C. Bidou, Les aventuriers du quotidien, essai sur les nouvelles classes moyennes, París, PUF, 1984.

${ }^{3}$ E. Cassirer, Essai sur l'homme, París, Editions de Minuit, 1982. 


\section{Del salón a los grandes bulevares: la visibilidad de las clases burguesas en el espacio público}

Al principio del periodo -inicios de 1880- es el salón burgués de los Verdurin lo que el autor pone en escena. Aún no se trata más que de un muy pequeño salón organizado en torno de algunos comensales de escaso valor social. Pero se sabe que los Verdurin son ricos, aunque de un origen social totalmente oscuro. Ellos residían en la época en la calle Montalivet, en la ribera derecha del Sena, en el octavo distrito de París, en "un magnífico departamento con entrepiso que daba al jardín...”. El amueblamiento allí era aún heteróclito, a la imagen del origen social de los invitados. "La Sra. Verdurin estaba sentaba sobre un alto asiento sueco de pino lustrado [...] que chocaba con los bellos muebles antiguos que ella tenía”, como el bello canapé de Beauvais, que Swann no dejaba de admirar la primera noche que fue invitado para cortejar a Odette. "Él la llevó hasta su pequeño hotel, en la calle La Pérouse, detrás de L'Etoile". Swann, quien era entonces uno de esos raros burgueses que habían franqueado el umbral de las casas aristocráticas más elegantes, vivía en esa época en el malecón ${ }^{4}$ de Orleáns en la isla San Luis, entre las dos márgenes del Sena, y según Odette, "en medio de muebles rotos y alfombras usadas". Por otra parte, ella "no comprendía que Swann viviera en el hotel del malecón de Orleáns que, sin osar confesárselo, ella consideraba indigno de él". Su residencia, entre las dos riberas, simbolizaba de alguna manera este rol de mediador, entre dos clases sociales, que ahora era el suyo.

La tumultuosa relación entre Swann y Odette, fieles invitados a las cenas de los Verdurin, fue en última instancia el París de los grandes bulevares, de sus grandes cafés y restaurantes, de los cuales Odette era una asidua visitante. Una noche, Swann, al no encontrarla en la casa de los Verdurin, donde el mismo "grupo" se encontraba regularmente todos los miércoles, "quiso ir a buscarla a todos los restaurantes de los bulevares [...], hasta la casa Prévost [...], él avanzó hasta la Casa Dorada, entró dos veces a la Casa Tortini y sin haberla visto delante, venía de salir del Café Inglés". Los “fieles" también apreciaban estos encuentros y lugares de reunión en los nuevos cafés de los grandes bulevares, como las salidas de los restaurantes del Bosque de Boulogne, los paseos que allí se hacían y que conducían a veces hasta las Colinas de

${ }^{4}$ Traducimos la palabra francesa quai por malecón (n. de la t.). 
Saint-Cloud. A veces la señora Verdurin organizaba fiestas de campo en Chatou o visitas culturales a Pierrefonds o a Compiègne.

Todos los salones burgueses de la novela -por otra parte, al igual que los de la pequeña nobleza de robe $e^{5}$ estaban entonces localizados en la ribera derecha, en los nuevos barrios recientemente ordenados por Haussman. Para estas capas sociales, la sociabilidad del salón se prolongaba o reforzaba su visibilidad, en asiduas visitas a los nuevos lugares de moda de los grandes bulevares, pero igualmente en los recorridos y visitas por todo el centro-oeste de la capital (la calle Royal, los Campos Elíseos y todas las avenidas que conducen al Bosque de Boulogne). Las cenas entre amigos se pasaban alternativamente en la casa o en el restaurante. Sin embargo, no era raro darse cita en uno de los grandes cafés, donde también se podía llegar a encontrarse con alguien, en cualquier momento del día, para discutir acerca de los temas del momento.

Toda esta parte de la novela retrata la emergencia histórica del espacio público burgués en la ciudad del siglo XIX, y en particular en París, donde este espacio público se constituyó en la separación misma de la esfera privada y familiar, categoría que no existía como tal en la sociedad cortesana, así como lo ha desarrollado Habermas. ${ }^{6}$ La invención de una complementariedad entre el espacio privado y el espacio público se produce entre las capas burguesas, y no ha sido, a priori, el producto de la aristocracia, como se observará más adelante. "La nobleza urbana, y sobre todo la aristocracia parisina que marcaba las orientaciones del resto de Europa, por cierto, continuaba llevando su tren de vida y sólo sentía desprecio por la intimidad de la vida familiar burguesa". ${ }^{7}$ Pero la esfera pública burguesa se construye tanto

\footnotetext{
${ }^{5}$ La nobleza de robe (o robine) es una nobleza más reciente que la antigua nobleza o nobleza de "espada" (la de los combatientes), la única nobleza auténtica a los ojos de quienes forman parte de ella. La nobleza de robe es la que ha adquirido su condición noble más recientemente y por medio de nominaciones reales (por sus funciones y cargos).

${ }^{6}$ Jurguen Habermans, L'espace public, archéologie de la publicité comme dimension constitutive de la société bourgeoise, París, Payot, 1986.

${ }^{7}$ Habermas evocando a Goethe en su Wilhem Meister, recuerda la no pertinencia de la separación público/privado para la nobleza. La esfera pública aristocrática estaba dominada por la "representación": "un noble debe pagar de su persona y de lo nuevo que ella representa, sea en la guerra, sea en la Corte: Él tiene pues razones para hacer mucho caso y para mostrar que hace mucho caso [...] El hombre noble es la autoridad en la medida en que él la representa; él la significa, la encarna a través de su personalidad expandida... Él es 'público' en virtud de la representación que encarna”, J. W. Goethe, Wilhem Meister, Les années d'apprentissage, París, Gallimard-La Pléiade, 1963, citado por Habermas, op. cit., p. 24. Sin embargo, Habermas recuerda también que aquí Goethe
} 
mental como espacialmente, en el intercambio de informaciones, y la sociabilidad particular que autorizaba la asistencia frecuente a los cafés, clubes, restaurantes de un género nuevo, que conocieron las grandes ciudades del siglo XIX (en donde los periódicos frecuentemente estaban a disposición de los clientes) y que no tenían parecido con los círculos o clubes muy cerrados de la aristocracia. Esta esfera pública debe entonces mucho a la creación de gacetas y periódicos que han estado en el origen de una "información pública", luego de una "opinión pública", que vino a deslindarse de una información producida en torno a la exclusiva correspondencia privada, como ocurría en el antiguo régimen. La novela de Proust insistirá sobre la importancia de esta "información pública”, por ejemplo durante el caso Dreyfus, posteriormente durante la Guerra.

\section{De los jardines de los Campos Elíseos al Bosque de Boulogne: aprendizaje y puesta en escena de la urbanidad burguesa}

Se volverá a encontrar a Odette algunos años más tarde. Ella ha devenido en la señora Swann, y nadie más recordará en ella a la pequeña obrera de la costura ni a la semimundana entretenida en el salón de los Verdurin. Por otra parte, no frecuentaba más a la "Patrona", tal como le recomendaba su marido. Ella enviaba a su hija Gilberte a los Campos Elíseos con su institutriz. Los jardines de los Campos Elíseos van a ser analizados por el autor en esta parte de la novela como otra variante del espacio de la sociabilidad burguesa. Ya no se trata de una burguesía que se mezcla con otros o polemiza, como la de los grandes bulevares, sino de una burguesía con pretensiones aristocráticas. Es sobre todo un lugar de aprendizaje de la urbanidad por medio del juego. En los Campos Elíseos los niños juegan haciendo amigos y recibiendo invitaciones. Antes de evocar el reencuentro del narrador con Gilberte, a quien ya había visto anteriormente en Combray pero cuyos padres no frecuentaban más a Swann -justamente porque él se había casado con Odette-, es esta sociabilidad infantil lo que el

entiende la palabra "público" en el sentido tradicional, y no en el que era dominante en su época, es decir, ligado al Estado. Habermas evoca también el pasaje histórico del espacio del poder feudal al poder del Estado, que se hacía por una alianza entre el monarca, la pequeña nobleza y las nuevas capas burguesas cultivadas, contra la sociedad de la corte y la alta aristocracia. Este análisis, de hecho, es muy próximo al de Elias (en La Dynamique de l'Occident, Calmann-Levy, 1976), que Habermas no cita. 
autor pone en escena: “[...] cuando salió del paseo, dirigiéndose a una muchacha de cabello rojizo que jugaba al volante enfrente del estanque, otra que se iba poniendo el abrigo y guardando su raqueta, y que le gritó con voz corta: Adiós, Gilberte, me voy: no se te olvide que esta noche, después de cenar vamos a tu casa”. El pequeño muchacho iba a entrar rápidamente en la pandilla de niños de Gilberte, y ser parte de sus juegos: "una vez que no eran bastantes para jugar a policías y ladrones, me mandó preguntar si quería completar el bando, y desde entonces jugué con ella siempre que ella iba”. Los juegos de los Campos Elíseos devienen complementarios e introductorios a las pequeñas reuniones mundanas infantiles. "Cuando [Gilberte] estaba invitada a alguna casa, y yo sin saberlo le preguntaba si vendría a jugar al día siguiente, me contestaba: Espero que no, creo que mamá me dejará ir a casa de mi amiga”. El narrador no amaba estas muy frecuentes invitaciones a las cuales era convidada su nueva compañera de juegos. Para él estas invitaciones constituían contratiempos en sus reencuentros y en sus juegos. Pero la pequeña Gilberte ya sabía muy bien administrar su agenda infantil. Aunque él le preguntaba una vez más si ella regresaría al día siguiente, "saltando de alegría, me contestó: Mi amiguito, esté tranquilo porque mañana no vengo, estoy invitada a una merienda magnífica, pasado mañana tampoco, porque voy a casa de una amiga".

Los niños de los jardines de los Campos Elíseos pasan la mayor parte del tiempo allí acompañados de una criada, o un ama de llaves en el caso de los pequeños, una institutriz para los más grandes. Algunas veces, pero más raramente, es una abuela quien lleva a los niños al parque. Para Gilberte se trataba de una "Señorita" muy bien puesta, con un sombrero con una pluma azul. El narrador, por su parte, iba allí con Francisca. "Yo trataba de persuadir a mi madre para que le comprara a Francisca un impermeable y un sombrero con una pluma azul, y mejor todavía, para que no me mandara a los Campos Elíseos con aquella criada que me avergonzaba". Los padres podían aparecer algunos instantes, controlando así las instrucciones dadas a los acompañantes, verificando también con quién jugaban sus hijos. Algunas veces, al final de la tarde, el señor Swann venía a buscar a su hija al jardín. "Él decía a Gilberte que la dejaba jugar otra partida y quedarse un cuarto de hora más; se sentaba, como todo el mundo, en su silla de hierro [...] mientras nosotros empezábamos a jugar en la pradera". 
El trayecto que separaba los jardines de los Campos Elíseos del Bosque de Boulogne obsesionaba al narrador, enamorado de la pequeña Gilberte y de todo lo que ella representaba. "Yo siempre tenía a la mano un plano de París, que me parecía un tesoro, porque en él podía distinguirse la calle donde habitaban el Sr. y la Sra. Swann. Y por gusto, y por una especie de caballeresca fidelidad, a propósito de cualquier cosa, yo pronunciaba el nombre de esta calle, tanto, que mi padre, que no estaba enterado de mi amor, como mi abuela y mi madre, me preguntó: ¿Por qué siempre hablas tú de esa calle?, no tiene nada de extraordinario, es muy agradable para vivir porque está a dos pasos del Bosque de Boulogne, pero hay otras diez en la misma situación". Los días en que Gilberte no venía a jugar a los jardines, el narrador iba en peregrinación al Bosque de Boulogne. "Como yo sabía que la Sra. Swann paseaba casi a diario por el paseo de las Acacias, alrededor del lago grande, y por el paseo de la Reina Margarita, es que encaminaba a Francisca hacia el Bosque". "Me habían dicho que en aquel paseo podría ver a ciertas elegantes, que aunque no eran todas casadas, se citaban habitualmente junto a la Sra. Swann, pero más frecuentemente con su nombre de guerra; su nuevo nombre, cuando lo tenían, no era más que una especie de incógnita que los que hablaban de ellas tenían buen cuidado de quitarles para hacerse comprender [...] yo aceptaba de antemano, como una revelación, la aparición de su atuendo, de su carruaje". La señora Swann era siempre a sus ojos la más bella, "su cabello rubio, ahora sin más que un mechón gris, ceñido por un listón de flores, por lo general violetas, de donde caían largos velos, con una sombrilla color malva en la mano, y en los labios una sonrisa ambigua”. Ciertos paseantes reconocían a Odette, a pesar de su transformación y el lujo de su atuendo, y decían: "¿Sabe Usted quién es? iLa Sra. Swann! ¿No se da cuenta? Es Odette de Crécy...”. El autor evoca "esta complejidad del Bosque de Boulogne, que lo hace un lugar artificial y, en el sentido zoológico y mitológico de la palabra, un Jardín”. De los Campos Elíseos al Bosque de Boulogne, el espacio recreativo urbano de los parques y jardines públicos es antes que nada la puesta en escena de la urbanidad burguesa, en donde se deja ver, en donde se muestra y se enseña a los niños que se lo puede y se debe frecuentar. 


\section{El espacio aristocrático urbano como negación de la ciudad}

El espacio aristocrático del primer periodo es pintado de manera mucho más sucinta. Sólo es abordado por su periferia. En la primera parte de la novela se ve a la joven Oriana de Guermantes, quien todavía no es duquesa, hacer una rápida aparición en una matiné musical en la casa de la señora de Saint-Euverte, todo un pequeño salón de la nobleza reciente situado cerca del Parque de Montceau, en este barrio nuevo construido gracias a las fortunas recientes, y lo suficientemente apartado tanto física como socialmente del faubourg Saint-Germain. La aristocracia es puesta en escena por primera vez en el tercer volumen de la novela, titulado "el mundo de Guermantes", por medio del faubourg de SaintGermain o, en breve, el Faubourg. Con la evocación constante del caso Dreyfus, se puede comprender que el siglo llegaba a su término. El empleo metonímico del nombre de una avenida parisina para designar al grupo social, denota el fuerte vínculo entre éste y su territorio. ${ }^{8}$ El espacio residencial real de la vieja aristocracia de espada, la única legítima, en los hechos supera ligeramente este barrio del séptimo distrito de la ciudad, desde el bulevard Saint-Germain y las calles vecinas. Una primera aproximación del territorio parisino de la familia Guermantes está bastante extensamente desarrollado en el inicio de este volumen. El pretexto novelesco consiste en la instalación de los padres del narrador en un departamento situado en un cuerpo de construcciones linderas con la "residencia" del duque de Guermantes, quedando sobre un patio compartido por el conjunto de los residentes. La localización de esta casa permanece bastante imprecisa. "La presencia del cuerpo de Jesucristo en la hostia no me parecía un misterio más oscuro que aquel primer salón del barrio situado en la margen derecha, cuyos muebles podía yo escuchar sacudir en las mañanas, desde mi cuarto". Se imagina entonces, la "residen-

${ }^{8}$ En L'Espace Proustien, G. Poulet recuerda cómo la novela proustiana sobresale al presentar esta particularidad del encubrimiento entre el nombre de la familia y el territorio, "los nombres de familia, especialmente los nombres de familias nobles, tienen esta particularidad de ser a la vez el nombre de un lugar y el nombre de una persona, y amalgamar así en una entidad única los dos componentes, de los cuales la imaginación proustiana requiere", y proponer la cita de la novela: "La Sra. Guermantes se sentó. Como su nombre era acompañado de su título, agregaba a su persona física, su ducado, que se proyectaba alrededor de ella y hacía reinar la frescura sombría y dorada de los bosques de Guermantes en medio del salón, en torno al taburete en donde ella estaba”. G. Poulet, L'Espace Proustien, París, Gallimard, 1988, p. 45.

${ }^{9}$ Traducimos el término francés hôtel por residencia, en el sentido de palacete (n. de la t.). 
cia" de Guermantes situada en la proximidad del faubourg SaintHonoré, detrás de las Tullerías (una pariente es evocada como residente de esta calle). "Este primer salón del 'Faubourg' situado sobre la ribera derecha", cacaso no es un signo de que éste no es totalmente lo que era? El duque y la duquesa, contrariamente a los miembros más tradicionales de su casta, manifestaban un cierto espíritu de innovación:

“... del Sena puede haber sido para ellos como una tímida descentralización territorial”. ${ }^{10}$

Desde la casa del joven hombre se podía ver a la duquesa; incluso, cruzando el patio. Burguesía y aristocracia son aquí físicamente cercanas, sin embargo, socialmente siempre son extremadamente lejanas. Existía "entre la duquesa y yo la barrera en donde termina lo real", constata el narrador, acerca de este periodo. "La línea de demarcación que me separaba del faubourg Saint-Germain, por ser solamente ideal, sólo me parecía más real; sentía claramente que el Faubourg era ya el tapete de los Guermantes, extendido al otro lado de ese ecuador, y del cual mi madre se había atrevido a decir, después de haberla visto como yo, un día en que la puerta estaba abierta, que estaba en muy mal estado".

El autor expone, en el preámbulo de este primer desarrollo sobre el espacio de la alta aristocracia, dos de sus trazos: su decadencia económica, que no altera en nada la conciencia de su superioridad social. "No obstante el engreimiento del jefe de comedor de los Guermantes, Francisca había podido, desde los primeros días, hacerme saber que aquellos no habitaban su residencia en virtud de un derecho inmemorial, sino por un arrendamiento bastante reciente, y que el jardín al que daba la residencia por la parte que yo conocía, era bastante pequeño y semejante a todos los jardines contiguos; y supe que allí no se veía caza señorial, ni molino fortificado, ni palomar sobre columnas, ni horno, ni castillete, ni puentes...". A pesar de la relativa banalidad de su

10 "En el siglo XVIII, el faubourg Saint-Germain no sólo era el remanso de las grandes familias: el faubourg Saint-Honoré rivalizaba con él, tanto por los orígenes de los habitantes como por la belleza de su arquitectura y el tamaño de los jardines. La ribera derecha llegó a ser el lugar de asentamiento de la aristocracia de robe, de la nobleza napoleónica y aun de las finanzas". "Délégation a l'action artistique de la ville de Paris, Société d'histoire et d'archélogie du VII ème arrondissement", Le faubourg Saint-Germain, la rue de Varenne, París, Musée Rodin, 1981, citado por M. Pinçon y M. PinçonCharlot, Quartiers bourgeois, quartiers d'affaires, París, Payot, 1992, p. 19. 
morada, el duque y la duquesa se comportaban allí como señores feudales en su feudo: "Pero si la residencia de Guermantes comenzaba para mí en la puerta del vestíbulo, sus dependencias debían extenderse mucho más lejos, a juicio del duque, el cual, tomando a todos los inquilinos por granjeros, rústicos, compradores de bienes nacionales, cuya opinión no cuenta, se afeitaba por las mañanas en ropa de dormir en su ventana, bajaba al patio [...] y hacía que uno de sus picadores pusiera al trote frente a sí, a algún caballo nuevo que había comprado, teniéndolo de la brida [...] Desde otros puntos de vista que el de la beneficencia, el barrio no le parecía al duque más que una prolongación de su patio, un picadero más extenso para sus caballos”.

El narrador sentía placer por observar desde su ventana las costumbres extrañas de esta "tribu", con la cual, hasta entonces, él sólo tenía muy poca cercanía. Un día el narrador pudo ver a dos parientes de Oriana: "Descendidas de las alturas de la Residencia de Brequigny para ver a la duquesa [...], provistas de su bastón de alpinismo, Walpurge y Dorotea [...] emprendieron de nuevo el camino escarpado de su cumbre. Nunca había pensado en preguntarles a los Guermantes a qué correspondían estos bastones, tan frecuentes en el faubourg Saint-Germain. Puede ser, considerando a toda la parroquia como su dominio y no gustándoles tomar coches de caballos, y haciendo ellas largas caminatas, para las que alguna antigua fractura (debida a la costumbre inmoderada de la caza y a las caídas del caballo que esto supone frecuentemente), o simplemente, los reumatismos provenientes de la humedad de la ribera izquierda y de los antiguos castillos, que necesitaban el bastón. Puede ser que no habiendo salido en una expedición tan dilatada y habiendo bajado solamente a su jardín (poco alejado del de la duquesa) para recoger las frutas necesarias para las conservas, venían, antes de regresar a su casa, a dar las buenas noches a la Sra. de Guermantes”.

El autor nos hace comprender que la residencia urbana de los aristócratas es reciente -sólo uno o dos siglos- con relación a la profundidad de su conciencia histórica. Esta conciencia, generalmente, no era más que estacional, sus castillos abrigaban la sociabilidad estival. Durante los veranos, los Guermantes volvían a encontrar sus signos, sus insignias, cerca de Combray, sobre sus tierras, sus lugares en la iglesia, los mismos desde tiempos inmemoriales. En la ciudad, los aristócratas reproducían esta relación tradicional con el espacio, que es a la vez e indisociablemente, una relación social (feudalidad) y espacial (la puesta en valor del 
feudo). La ciudad es negada como tal, como también es negada simbólicamente la presencia de otras clases sociales en el mismo territorio. En efecto, la alta nobleza de este fin del siglo XIX vivía socialmente muy replegada sobre sí misma y estaba muy persuadida de su carácter esencial y de su irreversible supremacía, de modo que una pequeña dosis de mezcla social, en el ámbito de las viviendas y del barrio, era aceptable. No existía, a sus ojos, ningún riesgo de confusión. Una relativa mezcla social esencialmente tenía una dimensión funcional. Se llegaba así al punto en que ciertos aristócratas, como lo recuerda el autor con relación al duque y la duquesa, alquilaran una parte de sus residencias a familias burguesas más acomodadas que ellos. ${ }^{11}$ En el patio del duque y la duquesa, y los parientes del narrador, un local estaba ocupado por un artesano que hacía chalecos, Jupien, luego amante y después secretario y chofer de Charlus.

Numerosos pequeños oficios y comercios estaban presentes en los barrios donde residían los miembros de la aristocracia, en la esquina de la calle, casi a su servicio, como en los pueblos en los que dominaban sus castillos. Las otras clases sociales estaban, para ellos, presentes pero sin existencia real. Simplemente, no pertenecían al mismo orden. "Fuera de los temas populares finamente escritos para instrumentos variados, desde el cuerno del sillero y hasta la pequeña flauta del pastor, orquestaban ligeramente el aire matinal [...]. Las cortinas de hierro de la carnicería, de la cremería, se levantaban ahora [...]. Es el encantamiento de los viejos barrios aristocráticos, de este lado, el de ser también populares”. Así, paradójicamente, los barrios aristocráticos son más mezclados que ciertos barrios burgueses. El narrador, tomando conciencia de esto, aprecia este espectáculo variado de la calle: "Yo iba a colocarme un instante en la ventana. Al inicio, había silencio, en donde el silbato del vendedor de vísceras y el silbato del tranvía hacían resonar el aire [...]. Me parecía que si alguna vez debía dejar este barrio aristocrático -a menos que fuera por uno totalmente popular-, las calles y los bulevares del centro, en donde la frutería, la pescadería, etc., integradas a las grandes casas de alimentación, haciendo inútiles los gritos de los vendedores, que de cualquier forma no hubieran podido hacerse oír, me hubieran parecido bastante aburridas [...]. Las pequeñas

${ }^{11}$ El pasaje deja pensar que estos Guermantes son inquilinos. Un poco más lejos, el joven hombre que quiere acercarse a la duquesa, le dice: "qué pobre referencia que la de ser inquilino". 
vendedoras de pan se apresuraban a ensartar en sus canastas los panes destinados al almuerzo".

A la inversa de la relación que establecen con la ciudad las clases populares o ciertas capas burguesas, la ciudad no es para los aristócratas constitutiva de un cierto espacio público, sino restringida al simple espacio privado, o al espacio fantásticamente privado, cuando actuaban fuera de sus casas lo hacían como si estuvieran en un territorio conquistado -es decir, como si estuvieran en sus tierras-. Sin embargo, pensarlo de esta forma es un punto de vista burgués, como ya se ha visto. Es la distinción privado-público lo que no funciona como tal en el espacio aristocrático. Algunos aristócratas cometen imprudencias, como Roberto de Saint-Loup, sobrino de la duquesa y amigo del narrador, quien se mezcla con las clases populares tomando un tren de la periferia para ir a pasear con Rachel (una actriz de teatro) a uno de esos pueblos de los alrededores de París; o Charlus, frecuentando hoteles muy especiales. Empero, este tipo de comportamiento precisamente es parte de la decadencia de la aristocracia. El único lugar no doméstico frecuentado abiertamente por la aristocracia en la época de la novela de Proust, es el espacio del teatro. Pero, incluso allí, el autor demuestra cómo los miembros de la aristocracia llegan a apropiárselo a su manera, haciéndolo un espacio más privado.

\section{"Privatización" $"$ aristocrática del espacio público}

A lo largo de un extenso desarrollo, Proust nos cuenta "una velada en la Ópera", en donde se encuentran el narrador y su vecina, la duquesa de Guermantes, a quien él sólo conocía de vista. Se tiene aquí un minucioso y cómico análisis metafórico del espacio del teatro. A semejanza de la sociedad, éste también estaba dividido en la parte alta y la baja, entre el claro y el oscuro. Como en la sociedad, allí cada uno sólo está haciendo una representación, en su lugar asignado. El narrador, por su parte, estaba sentado en el patio de butacas, "este vasto espacio iluminado en donde se encuentran las personas vulgares”. Sigue luego un largo pasaje en que la aristocracia está asimilada a una extraña fauna marina, ella misma subdividida en varios subgrupos: En el nivel superior se

${ }^{12}$ Las comillas simplemente apuntan a recordar que el término no es muy adecuado, pues la aristocracia como tal no participa de esta categorización semántica. 
encuentran los “dioses del mar", luego los simples animales acuáticos, es decir, los estratos más bajos de esta clase. "La gente de mundo estaba en sus palcos (delante el balcón en terraza), como en los pequeños salones suspendidos en los cuales ha sido levantado un tabique". Ellos dominan así el conjunto de la sala. Pueden ver sin ser vistos, ya que sus palcos de platea están poco iluminados, mientras que el "patio de butacas" está en plena iluminación. "Las blancas deidades que habitaban estas sombrías moradas se refugiaban contra las paredes oscuras, permaneciendo invisibles. Sin embargo, a medida que el espectáculo avanzaba, sus formas vagamente humanas se desprendían suavemente, la una después de la otra, de las profundidades de la noche que ellas tapizaban y, elevándose hacia el día, dejaban emerger su cuerpo semidesnudo y venían a detenerse en el límite vertical y en la superficie claroscura en donde sus brillantes rostros aparecían delante del rompimiento burlón, espumoso y ligero de sus abanicos de plumas, bajo sus cabelleras de púrpura entremezcladas de perlas que parecían haber curvado las ondulaciones del flujo; luego comenzaban los sillones del patio de butacas, la morada de los mortales jamás separada del sombrío y transparente reino". Entre los dioses del balcón y lo oscuro de los monstruos iluminados del patio de butacas, no existía ninguna posibilidad de comunicación, ni el más mínimo contacto. La distancia era sideral, tan grande, insiste el autor, como entre los seres humanos y los minerales. Aquí también "los otros", "la gente vulgar" del patio de butacas, eran simbólicamente negados. Los aristócratas se permitían llegar tarde, después del inicio. Ellos reproducían en el espacio del teatro su propia sociabilidad. Ellos se invitaban y se recibían, pero sólo entre ellos, en los pequeños salones privados que formaban sus palcos de platea. ${ }^{13}$ La semioscuridad les permitía mantener en su espacio público, un subespacio funcionalmente privado.

Poco tiempo después de esta velada en la Ópera, el narrador iba a ser presentado a la duquesa, su vecina inmediata, en el curso de una recepción en la casa de la tía de ésta, la marquesa de Villeparisis. Incidentalmente son evocados los lugares de residencia de los diferentes miembros de esta alta aristocracia, todos ligados por vínculos de parentesco, y numéricamente restringida. Se puede constatar su fuerte concentración en un perímetro que apenas

${ }^{13}$ A propósito de la especificidad del espacio del teatro francés y la importancia de la sala con relación al escenario, véase $\mathrm{H}$. Lagrave, Le théatre et le public de Paris de 1715 â 1750, París, Klincksieck, 1972. 
superaba el séptimo distrito de la ciudad: "Con todo, del hotel del malecón de Malaquais a los salones de la calle Tournon, de la calle de la Chaise y del faubourg Saint-Honoré, un vínculo tan fuerte unía las tres divinidades venidas a menos" (la señora Villeparisis y dos de sus amigas). Un poco más adelante, el texto trata de otra tía, la señora De Montmorency: "Ella vivía en el faubourg Saint-Germain en una vieja mansión llena de varias construcciones separadas por pequeños jardines". ${ }^{14}$ Saliendo de la casa de la marquesa, el narrador se volvió hacia la casa del barón de Charlus (hermano del duque de Guermantes), que se había ofrecido para enseñarle los pormenores de las reglas del "mundo" (el suyo). Él residía en pleno faubourg Saint-Germain, en la antigua "residencia" de Chimay; algunas anécdotas nos muestran el decorado: "Yo volví a atravesar el gran salón verdoso. Le dije, por puro azar, cuánto me resultaba bello. ¿No es así?, me respondía él. Tenemos por lo menos que apreciar algo. Los revestimientos de madera son de Bagard. Mire, lo que es bastante agradable es que fueron hechos para los asientos de Beauvais y para las consolas. Como lo notará, repiten el mismo motivo decorativo que éstos". Sobre los muros del barón se encontraba el retrato de los tíos, el rey de Polonia y el rey de Inglaterra, pintados por Mignard. También hace referencia incidental a dos Rembrandt entre los cuales colgaba "un arco iris de Turner". En este tipo de espacio, el valor de los objetos y de los muebles venía de su carácter tradicional y de su capacidad para perpetuar la memoria grupal. La innovación formal como tal estaba proscrita.

A partir de esto, el joven (el narrador) será invitado sucesivamente a cenar a la casa de la duquesa; luego, a una velada en la casa del príncipe y la princesa de Guermantes (el príncipe es primo del duque). Acudiendo a pie a esta recepción, él atraviesa la Plaza de la Concordia, cuyo obelisco en esta noche de verano "tiene un aire de turrón rosa". El príncipe y la princesa viven en la calle de Varenne, en una espléndida "residencia" con un gran jardín. "En una claridad reservada por los bellos árboles, de los cuales varios eran tan antiguos como él, plantado aparte, se veía de lejos el célebre chorro de agua de Hubert Robert, esbelto, inmóvil [...] atravesaba los jardines y subía la escalera”. En esta noche, se observa a Oriana llevar al narrador a visitar los lugares. Ella lo conduce a través de la sucesión de salones, haciéndole

\footnotetext{
${ }^{14}$ Sobre las características de las viviendas de este barrio, véase "Délégation a l'action artistique de la ville de Paris, Société d'histoire et archéologie du VII ème arrondissement", Le faubourg Saint-Germain..., op. cit.
} 
apreciar "el esplendor del palacio de su prima", subrayando que ella "prefería su húmedo hoyo". Ella entendía por "hoyo" el mismo tipo de "residencia", más pequeña sin duda, pero sobre todo con un ala rentada a familias burguesas. Sin embargo, en el patio, varios locales estaban alquilados a artesanos. El príncipe y la princesa residían en lo que representaba el modelo de vivienda aristocrática desde hacía dos siglos: un gran hotel, separado de la calle por un patio a donde podían penetrar los carruajes, dejando a los habitantes o visitantes al pie de una gran escalera, sin que ellos tuvieran que pisar la calzada. En lo alto de aquélla había una escalinata sobre la cual se abría una gran antesala, que conducía a una sucesión de salones. Éstos daban al fondo de la residencia y a los jardines. ${ }^{15}$ En la "residencia" del príncipe de Guermantes, estos jardines eran particularmente grandes y con árboles muy altos. La familia había hecho construir allí, durante el siglo XVIII con Hubert Robert, uno de esos chorros de agua y cuenca de rocas, entonces a la moda.

\section{Proximidad espacial y distancia social: una emigración burguesa a la ribera izquierda}

Las residencias burguesas de este mismo periodo de la novela, a la vuelta del siglo, habían mejorado con relación a las de la época anterior. Los Swann vivían, según se ha visto, cerca del Bosque (de Boulogne), en una muy bella mansión. Ellos tenían un jardín de invierno con muchas plantas, en el que Odette hacía servir el té en porcelana inglesa. El amueblamiento era de mejor gusto, más lujoso pero siempre convencional. "En la casa de la Sra. Swann, el Extremo Oriente retrocedía más y más, ante la invasión del siglo XVIII [...] y los cojines estaban sembrados de ramilletes Luis XV y no como antes, de dragones chinos”. El salón Verdurin de esta segunda época es presentado por el autor en su variante estival. La pareja había alquilado en Normandía, junto al mar, la casa de campo de la Raspelière. ${ }^{16}$ La señora Verdurin había refinado su gusto, había vuelto a sacar del desván algunos

${ }^{15}$ M. Eleb-Vidal y A. Debarre-Blanchard, Architecture de la vie privée, XVIIèmeXIXème, París, АAM 1989.

${ }^{16} \mathrm{~J}$. Dubois en una obra reciente (Pour Albertine, Proust et le sens du social, París, Ediciones du Seuil, 1997) muestra cómo a la vuelta del siglo, la burguesía y las clases medias acomodadas, mediante las prácticas de ocio nuevas como el deporte y el juego de playa, han contribuido a una cierta neutralización de las fronteras entre clases. 
bonitos muebles y adornos, y el arreglo conseguido fue la admiración de los Cambremer, sus propietarios. En su papel de decoradora, precisa el autor, ella era "inteligentemente conservadora”, aunque también innovadora, dejando transformar las antiguas jardineras en un jardín de cura con flores y hierbas salvajes. La pareja continuó allí con las mismas cenas de los miércoles, las mismas distracciones musicales, con los mismos "fieles".

En lo que refiere a las residencias parisinas, el autor muestra que si la mayoría de la rica burguesía o la pequeña nobleza de robe se había apropiado progresivamente de los barrios nuevos del oeste, algunos nuevos estratos burgueses habían seguido otras estrategias. Era el caso de los Verdurin y de la mayor parte de la gente cercana a ellos. Contrariamente a los salones social y políticamente conservadores, como el de Odette Swann, el de los Verdurin había emigrado a la ribera izquierda, al malecón Conti. De tal suerte que se acercó físicamente al faubourg Saint-Germain, sin embargo, se mantenía socialmente muy distante. Con todo, esta proximidad física tendrá su importancia. Vamos a ver de qué forma. Los "fieles" residían también en la mayor parte de la ribera izquierda, como el profesor Cottard, en la calle del Bac. Durante más de veinte años, después de los inicios de las primeras cenas y hasta esta época tratada por la novela, a la vuelta del siglo, el trabajo de "salón" de la señora Verdurin había sido efectuado en silencio, lejos del "mundo" que ella aparentaba no buscar. A pesar de todo, su salón había mejorado. Si al inicio sólo reunía algunos adeptos, ahora su número se había multiplicado, y todos, habiendo partido de la nada, consiguieron relevantes carreras profesionales: Brichot como universitario en la Sorbona; Cottard llegó a ser un célebre profesor de medicina; Elstir como pintor. Se tocaba en este salón, desde hacía ya mucho tiempo, la música de Vinteuil, que por esa época había adquirido una gran reputación, aun en el seno de la más alta aristocracia. De igual modo, Elstir llegó a ser célebre ahí, e incluso había logrado algunas ventas, como las que le hicieron el duque y la duquesa, que aunque no lo querían, lo hacían por esnobismo. Pero la señora Verdurin había captado desde hacía mucho tiempo su talento. Incansablemente ella lo había sostenido y aconsejado desde sus inicios.

A la imagen de su elección referente a las vanguardias en materia artística, las tomas de posición política de la señora Verdurin fueron audaces. Ella fue una de las primeras en tomar la defensa del capitán Dreyfus, lo que demoró el ascenso de su sa- 
lón. Éste abrigaba verdaderas “sesiones de salvamento público en donde se reunían Picquart, Clemenceau, Zola, Reinach y Labori". ${ }^{17}$ Pero, al finalizar el caso, todo el mundo iba a reconocer lo atinado de sus juicios, tanto políticos como artísticos. Sin otras armas que éstas que ella misma había forjado, la señora Verdurin alcanzó a construir un salón de buena reputación, que el tiempo iba a reconocer como tal. Y es así que un buen día el barón de Charlus, queriendo lanzar en el mundo a su protegido, el músico Morel, un fiel de los Verdurin quien debía tocar esa noche un septeto inédito de Vinteuil, invitó a "todo el faubourg Saint-Germain" a escucharlo en este salón burgués. Si esta invitación fue posible, es porque esta casa se situaba en las cercanías inmediatas del Faubourg, como lugar. Al fin de cuentas, los del Faubourg, como grupo social, habrían podido asistir allí como simples vecinos, a su pesar, sin conciencia de los efectos sociales de una colusión de ese tipo.

Este salón Verdurin estaba ubicado en una muy bella mansión. Su localización era prestigiosa, su mobiliario magnífico, la comodidad muy agradable, las comidas eran deliciosas. Si no hubiese sido así, habría sido impensable que Charlus condujera ahí a "todo el Faubourg”. La Residencia Verdurin del malecón Conti es evocada extensamente por el narrador de la novela: "su dueño la asemejaba a la de los embajadores de Venecia [...] la residencia contaba con un cuarto de fumar, que Verdurin pretendía como en Las mil y una noches, que había sido recuperada como tal de un conocido 'palazzo' [...]. Pasamos a la mesa y vemos [...] toda una platería decorada con esos mirtos de Luciennes, que podría reconocer la Dubarry [...]. Una extraordinaria jarra comprada en la venta del Sr. de Montalivet vierte en el vaso de Venecia, frente a mí, unas auténticas joyas de vinos tintos... Esta refinada comida, servida en esta vajilla que ningún príncipe pudiera poseer en la actualidad en sus bargueños, [es] un delicado placer”. En ese lugar se servían platos más refinados que en las más grandes mansiones parisinas. El ama de casa había inventado un sabor y un arte de vivir que pronto le envidiaría la aristocracia. También debe recordarse que los Verdurin, antes que los demás, tuvieron la electricidad y el teléfono, tan práctico para las

\footnotetext{
${ }^{17}$ La autora se refiere al caso Dreyfus, por el cual este capitán de origen judío fue injustamente acusado de alta traición y enviado a un presidio por largos años, antes de ser absuelto. Por la relevancia del caso y el claro tinte antisemita, los personajes citados por Proust constituyeron un comité para defender a Dreyfus y "salvar" al país del oprobio de esta injusta condena (n. de la t.).
} 
conversaciones entre "fieles", para discutir del "caso", y pronto también para discutir sobre la guerra. Después de haber franqueado por primera vez el umbral de este salón burgués, el Faubourg iba a regresar ahí "muy naturalmente", cosa que le habría sido mucho menos fácil si el salón hubiera permanecido en un barrio con dominante burguesa o de pequeña nobleza reciente, como es el caso del oeste de la ribera derecha, el "barrio del Bosque", donde vivían los Swann y algunos de sus amigos, o también la Plaine Monceau, donde habitaban los Sainte-Euverte.

\section{El regreso a la ribera derecha y la colusión de clases}

La guerra iba a llegar muy pronto. Los Verdurin, cuya fortuna era sólida, se replegaron en la comodidad de una gran "residencia" cerca de la calle Royal, en el centro geográfico de la capital, mientras que los aristócratas ni siquiera eran capaces de calentar sus grandes mansiones ni de ofrecer recepciones. Ahora asistían a las que ofrecía la señora Verdurin en el hotel Majestic. Les encantaba el carácter pomposo de las cenas servidas en el comedor privado de la "dueña”, además de que en esos tiempos de desconcierto ella se había convertido en la comentarista más discursiva de los eventos, así como en la analista política más creíble, pues leía cada mañana todos los periódicos. Las damas de la aristocracia la admiraban y no podían pasarse sin sus conversaciones. "Ninguna duquesa hubiera podido ir a la cama sin informarse por parte de la Sra. Bontemps o la Sra. Verdurin, por lo menos por teléfono, de lo que contenía el comunicado de esa noche, de lo que omitía, qué pasaba con Grecia, o qué ofensiva estaba en preparación [...]. En la conversación, la Sra. Verdurin al comunicar las noticias, decía, 'nosotros' hablando de Francia".

La última parte de la novela se sitúa al comienzo de los años veinte (la guerra había terminado desde hacía varios años). El narrador se prepara para asistir a una matiné en la casa de la princesa de Guermantes. Atraviesa las calles del barrio en coche, lo que le recuerda el camino que recorría antiguamente con Francisca para ir a jugar al jardín público. Encuentra a Charlus haciendo un pequeño paseo con Jupien, cuyo coche se había detenido. "Nosotros no iremos más allá de la glorieta".

Es en este momento cuando nos enteramos del final de la historia social de la novela. La señora Verdurin quedó viuda; se estaba volviendo a casar con el duque de Duras, “quien fue para 
ella una transición muy útil”. Viuda de nuevo, pero más y más rica, se había casado y "puesto a flote" con el príncipe de Guermantes, viudo y arruinado por la guerra. La nueva pareja se estaba construyendo un magnífico palacio en la avenida del Bosque (actual avenida Foch), entre "los nuevos ricos". Esta nueva mansión del príncipe de Guermantes comprendía, como la antigua, una sucesión de salones que daban sobre un bello jardín. En una escena homóloga a aquella que tuvo lugar en la recepción en la casa del príncipe y a la cual había asistido el narrador una veintena de años antes, la duquesa lleva a visitar el nuevo palacio a su primo. Inclusive en el salón de la nueva princesa ciertos invitados "habían terminado por asemejarse a sus barrios, llevaban puesto algo como el reflejo de la calle de la Arcada, de la avenida del Bosque, de la calle del Elíseo".

La estrella de la "matiné" era Rachel, esta actriz que había sido la amante de Robert de Saint-Loup. Tenía que presentar algunas réplicas. La Berma, esta gran artista que al narrador, tiempo antes, tanto gustaba verla en Fedra, sola y abandonada en esa noche, estimaba con amargura que "había que venir a París para asistir a situaciones como una Rachel dando una fiesta en la casa de la princesa de Guermantes”. En este salón, donde por primera vez aristocracia y burguesía se reunían, en forma incluso confusa, Oriana era la mejor amiga de Rachel y "las nuevas generaciones concluían de ello, que la duquesa a pesar de su nombre tenía que ser un semicastor que nunca había llegado a ser la flor y nata...". Constatando esas transformaciones sociales y observando la encarnación en la hija Gilberte que le presentaban, el narrador vio en ella algo como el punto de convergencia de su propia vida: "numerosos eran para mí los caminos que llegaban a la Srta. de Saint-Loup e irradiaban a partir de ella. Antes que todo, desembocaban en ella los dos grandes 'caminos' en los cuales había hecho tantos paseos y sueños, por su padre, Robert de SaintLoup, el lado de Guermantes; por Gilberte, su madre, el lado de Méséglise, por el “camino de Swann’”.

Traducción realizada por Alicia Lindón y revisada por Catherine Bidou 


\section{Bibliografía}

Benjamin, W. (1971), París, capital del siglo XIX, México, Editorial Madero.

— (1989), Paris capitale du XIxème siècle, le livre du passages, París, Editions Le Cerf.

Bidou, C. (1994), "Maisons et salons, des rapports aristocratiebourgeoisie dans le roman proustien", Actes de la Recherche en Sciences Sociales, núm. 105, diciembre, pp. 60-70.

- (1997), Proust sociologue, de la maison aristocratique au salon bourgeois, París, Descartes et Compagnie.

Cassirer, E. (1982), Essai sur l’homme, París, Minuit.

Champigneule, B. (1973), Paris: architecture, sites et jardins, París, Editions du Seuil.

Chevalier, L. (1967), Les pariesiens, París, Hachette.

Daumard, A. (1965), Maisons de Paris et propriétaires parisiens au XIxème, París, Cujas.

— (1979), Le bourgeois de Paris au xixème, París, Flammarion.

Dubois, J. (1997), Pour Albertine, Proust et le sens du social, París, Editions du Seuil.

Eleb-Vidal, M. y A. Debarre-Blanchard (1995), L'invention de l'habitation moderne, Paris 1880-1914, París, AAM-Hazan.

— (1989), Architecture de la vie privée, XVIIème-XIXème, París, AAM.

Elias, N. (1982), La sociedad cortesana, México, Fondo de Cultura Económica, México.

— (1976), La dynamique de l’Occident, París, Calmann-Lévy. 
Habermas, J. (1986), L'espace public, archéologie de la publicité comme dimension constitutive de la sociéte bourgeoise, París, Payot.

Goethe, J. W., Wilhem Meister. Les années d'apprentissage, París, Galimard-La Pléiade, 1963.

Mension-Rigau, E. (1994), Aristocrates et grands bourogeois. Education, tradition, valeurs, París, Plon.

— (1990), L'Enfance au château, París, Rivages.

Lagrave, H. (1972), Le théatre et le public de Paris de 1715 à 1750, París, Klincksieck.

Loyer, F. (1987), Paris XIXème siècle, l'immeuble et la rue, París, Hazan.

Ottaviani, I. y Ph. Poulain (1996), Le Paris de Marcel Proust, París, Editions des Musées de Paris.

Perrot, J. C. (1968), "Rapports sociaux et villes au XVIIÌ̀me siècle”, Annales, núm. 2, marzo-abril.

Pinçon, L. et M. Pinçon-Charlot (1992), Quartiers bourgeois, quartiers d'affaires, París, Payot.

Poulet, G. (1988), L'espace proustien, París, Gallimard-Tel.

Saint-Martin, M. de (1993), L'espace de la noblesse, París, Métaillé. 